\title{
Streib, J. (2020). Privilege Lost: Who Leaves the Upper Middle Class and How they Fall. Oxford University Press.
}

\section{Review by Sherry Linkon}

Working-Class Studies aims to deepen and expand understanding of working-class life, but our work has both benefitted from and contributed to theory and research about how class works how to define it, what shapes it, how it affects people's lives, and so on. This makes Jessi Streib's new book valuable even for those who might think of the professional middle class as the bosses who try to control and exploit workers, the clueless pundits or academics who dismiss workingclass voters as racist idiots, or just snobs who look down on 'us.' However, as Privilege Lost reminds us, stories about professional middle-class lives offer useful lessons about how class works. Those stories also challenge some common stereotypes.

One of the most common stereotypes is that upper-middle-class people 'had everything handed to them on a silver platter.' Privilege Lost argues that this is not true for many children growing up in well-off professional families. Indeed, Streib argues, many become downwardly mobile as adults, in part because their parents did not pass on their economic, academic, or cultural resources. For some, the resources are uneven. They may have significant academic and institutional knowledge but relatively low incomes. In other families, parents have all three resources but spend so much time at work that they don't pass them along to their children, and in some cases, children reject the resources their parents have to offer.

At the same time, Streib shows, maintaining class position is not just a matter of whether young people are handed 'everything.' Their life paths are also shaped by what they do with the resources available to them. She describes how half a dozen identities influence young people's choices, ranging from stay-at-home mom to explorer. These identities reflect multiple factors, including individuals' interests and abilities, the values and patterns of their communities, and their response to their parents' resources. Someone who identifies as an athlete might pursue a path that leads away from professional work, while a self-identified family man might prioritize relationships over academics at school.

Streib suggests that people form identities in response to the resources available to them, though in some cases, individuals seem to reject available resources because of their identities. For example, she writes that, for rebels, 'receiving or accepting little academic and institutional knowledge and then displaying an identity that celebrated not having it was a recipe for downward mobility' (p. 65). While the causal relationship may not always be so clear, Streib argues that resources and identities together explain why many lose their upper-middle-class status. As she puts it, 'Their resources poised them for a fall, and their identities pushed them over the cliff' (p. 58). 
Beyond her explanations of downward mobility, Streib's analysis, based on interviews with over 100 white people born into upper-middle-class families between 1984 and 1990 as part of the National Study of Youth and Religion, offers some useful insights for Working-Class Studies. Streib reinforces our understanding that class is not homogeneous, though instead of focusing, as we often do, on differences of time, place, or intersectional identities, Streib reminds us that even within a class category, we will find differences of economics, experience, and attitudes. Many of those differences reflect individual circumstances. Without in any way discounting the significance of class as a social category, Privilege Lost reminds us that even as we identify patterns that differentiate the working class from the middle class, as scholars like Barbara Jensen and Jack Metzgar have done, we should not ignore the power of individual circumstances and choices.

Streib's discussions of class problematize the idea of defining clear class categories, though that does not seem to be her intention. She does not present a class schema or even a well-developed model of what defines class categories. Rather, she focuses on people she describes as 'uppermiddle-class,' offering a fairly minimal definition: families with at least one parent with a college degree and a professional job. That includes a wide range of people, from school librarians and social workers to business executives and academics. Some earn six-figure incomes, but others hold positions that require advanced degrees and offer status but not high pay. In many of these households, one parent does not work, holds a more working-class position, or is employed only intermittently. To call all of them 'upper-middle-class' ignores some important differences, and it makes clear that class is not homogeneous. Downward mobility does not land these young people in a uniformly working-class position, either. Some barely scrape by, but most have college degrees and some have jobs that do not pay well but require some specialization and training. How do we assign a class position to a 28 -year-old who may simply not yet have found her path?

Streib's analysis also challenges the idea that middle-class culture prioritizes individual achievement (becoming) rather than connections to others (belonging). ${ }^{1}$ Streib's analysis does emphasize individualism, but it is not always wedded to the pursuit of achievement, by young adults or their parents. Privilege Lost presents family after family where parents seem to have largely ignored their children. Sometimes, such neglect comes from parents' investment in their own careers, but not always. In examining the family cultures of those she dubs 'rebels,' Streib describes upper-middle-class parents who make almost no effort to cultivate their children's academic or other abilities. As one young man explains, his parents 'trusted me to live my own life and make my own decisions' (p. 58). At the same time, her discussions of those who identify as stay-at-home moms and family men suggest that they prioritize family over individual achievement, an ethos that seems to emphasize belonging. To be clear, Streib does not set out to critique the model mapped out by these Working-Class Studies scholars, but her analysis does complicate our thinking about how class works and offers a model for studying variations within classes.

\footnotetext{
${ }^{1}$ These are among the terms Barbara Jensen and Jack Metzgar have suggested to denote the distinct cultures of the working and middle classes. See Jensen's Reading Classes: On Culture and Classism in America (ILR Press, 2012) and Metzgar's 'Politics and the American Class Vernacular,' in New Working-Class Studies, edited by John Russo and Sherry Lee Linkon (ILR Press, 2005), pp. 189-208.
} 
Privilege Lost is clearly written and packed with brief stories, but some of its nuances may get lost in a repetitive structure, as each chapter traces each participant through several set aspects of their lives. This stems, I think, from the challenge of a project based on a large corpus of interviews conducted by others for a study that is not about class. In trying to manage that data and maintain the focus of her study, Streib sometimes has to ignore potentially interesting detours and leave some questions unanswered. She notes some in her concluding chapters, such as the role of other kinds of parental resources, like wealth and social networks, and the trajectories of siblings. The humanist in me wanted fuller stories, with more consideration of complicating factors like how participants were influenced by their friends or their academic abilities.

Looking beyond the family, I also would have appreciated fuller discussions of how people's class paths were influenced by economic and social changes outside of their immediate circumstances. Streib discusses some of what she terms 'generational changes,' including changing roles for women and the decline in the number and quality of professional jobs. In part, this may reflect Streib's reliance on Pierre Bourdieu's ideas about habitus, which leads her to ignore issues of social conflict or power.

I can imagine another reading of these interviews that would pay more attention to how they reflected the broader social context - but that would be a different project. It is a testament to the value of Streib's work that, while it left me hungry to hear the rest of these young people's stories, it also got me thinking about different ways of approaching class.

\section{Reviewer Bio}

Sherry Lee Linkon is a Professor of English and American Studies at Georgetown University and the author of several books, including The Half-Life of Deindustrialization: Working-Class Writing about Economic Restructuring (Michigan 2018). She served for 17 years as co-director of the Center for Working-Class Studies and was the founding president of the Working-Class Studies Association. 